\title{
Correction to: The effect of cationically-modified phosphorylcholine polymers on human osteoblasts in vitro and their effect on bone formation in vivo
}

\author{
Jonathan M. Lawton ${ }^{1} \cdot$ Mariam Habib ${ }^{1} \cdot$ Bingkui Ma ${ }^{2} \cdot$ Roger A. Brooks ${ }^{2} \cdot$ Serena M. Best ${ }^{1} \cdot$ Andrew L. Lewis $^{3} \cdot$ \\ Neil Rushton ${ }^{2} \cdot$ William Bonfield $^{1}$
}

Published online: 22 February 2018

(c) Springer Science+Business Media, LLC, part of Springer Nature 2018

\section{Correction to: Journal of Materials Science: Materials in Medicine 2017;28:144}

https://doi.org/10.1007/s10856-017-5958-8

The article "The effect of cationically-modified phosphorylcholine polymers on human osteoblasts in vitro and their effect on bone formation in vivo", written by Jonathan M. Lawton, Mariam Habib, Bingkui Ma, Roger A. Brooks, Serena M. Best, Andrew L. Lewis, Neil Rushton and William Bonfield, was originally published Online First without open access. After publication in volume 28, issue 9, page 144 it was noticed that the copyright was wrong in the PDF version of the article. The copyright of the article should read as "ㅇ The Author(s) 2017. This article is an open access publication".

The Open Access license terms were also missing.

Open Access This article is distributed under the terms of the Creative Commons Attribution 4.0 International License (http://creativecommons.org/licenses/by/4.0/), which permits unrestricted use, distribution, and reproduction in any medium, provided you give appropriate credit to the original author(s) and the source, provide a link to the Creative Commons license, and indicate if changes were made.

The original article was corrected.
Jonathan M. Lawton and Mariam Habib contributed equally to this work.

The original article can be found online at https://doi.org/10.1007/ s10856-017-5958-8.

Andrew L. Lewis

andrew.lewis@btgplc.com

1 Department of Materials Science and Metallurgy, Cambridge Centre for Medical Materials, University of Cambridge, New Museum Site, Cambridge CB2 3QZ, UK

2 Orthopaedic Research Unit, University of Cambridge, Addenbrookes Hospital, Hills Road, Cambridge CB2 2QQ, UK

3 Biocompatibles UK Ltd, Chapman House, Farnham Business Park, Weydon Lane, Farnham, Surrey GU9 8QL, UK 